\title{
Subarachnoid hemorrhage: management considerations for COVID-19
}

\author{
Eric J. Panther ${ }^{1+}$ (1) Brandon Lucke-Wold ${ }^{2+}{ }^{*}$ (]) \\ ${ }^{1}$ College of Medicine, University of Florida, Gainesville, Florida 32610, USA \\ ${ }^{2}$ Department of Neurosurgery, University of Florida, Gainesville, Florida 32610, USA
}

${ }^{\dagger}$ These authors contributed equally to this work.

*Correspondence: Brandon Lucke-Wold, Department of Neurosurgery, University of Florida, Gainesville, Florida 32610, USA. Brandon.Lucke-Wold@neurosurgery.ufl.edu

Academic Editor: Jorge Manzanare, Miguel Hernandez University, Spain

Received: January 20, 2022 Accepted: February 18, 2022 Published: March 2, 2022

Cite this article: Panther EJ, Lucke-Wold B. Subarachnoid hemorrhage: management considerations for COVID-19. Explor Neuroprot Ther. 2022;2:65-73. https://doi.org/10.37349/ent.2022.00018

\section{Abstract}

Subarachnoid hemorrhage (SAH) has deleterious outcomes for patients, and during the hospital stay, patients are susceptible to vasospasm and delayed cerebral ischemia. Coronavirus disease 2019 (COVID-19) has been shown to worsen hypertension through angiotensin-converting enzyme 2 (ACE2) activity, therefore, predisposing to aneurysm rupture. The classic renin-angiotensin pathway activation also predisposes to vasospasm and subsequent delayed cerebral ischemia. Matrix metalloproteinase 9 upregulation can lead to an inflammatory surge, which worsens outcomes for patients. SAH patients with COVID-19 are more susceptible to ventilator-associated pneumonia, reversible cerebral vasoconstriction syndrome, and respiratory distress. Emerging treatments are warranted to target key components of the anti-inflammatory cascade. The aim of this review is to explore how the COVID-19 virus and the intensive care unit (ICU) treatment of severe COVID can contribute to SAH.

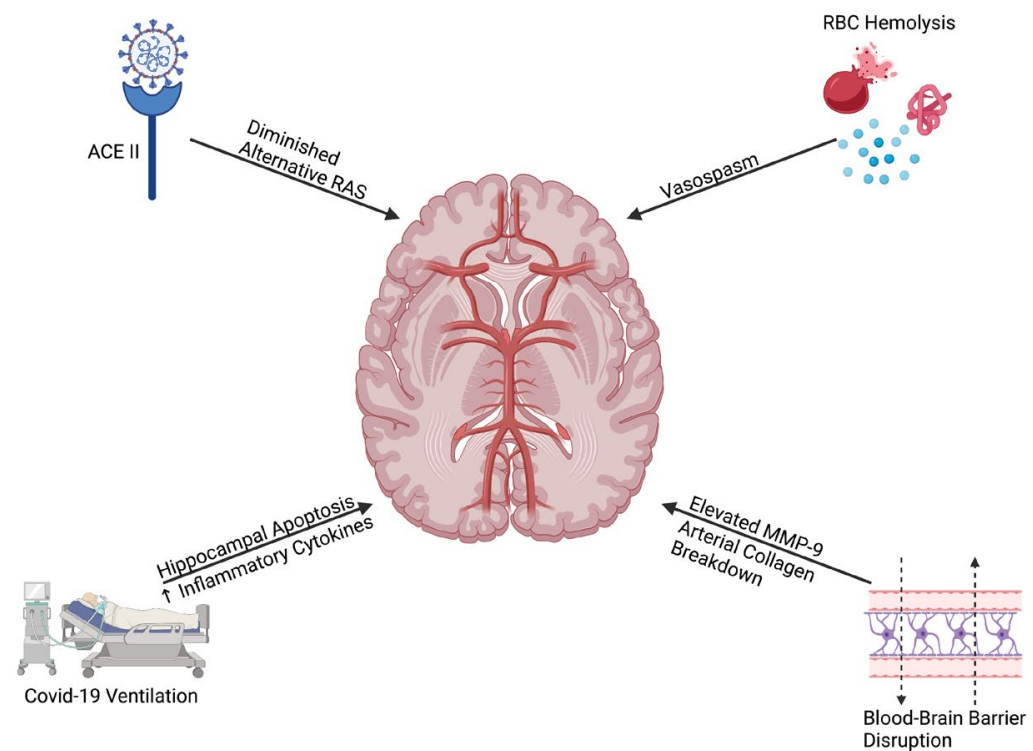

Graphical abstract. Broad effects of COVID-19 on inducing SAH. Created with BioRender.com. RBC: red blood cell; MMP-9: matrix metalloproteinase 9

(C) The Author(s) 2022. This is an Open Access article licensed under a Creative Commons Attribution 4.0 International License (https://creativecommons.org/licenses/by/4.0/), which permits unrestricted use, sharing, adaptation, distribution and reproduction in any medium or format, for any purpose, even commercially, as long as you give appropriate credit to the original author(s) and the source, provide a link to the Creative Commons license, and indicate if changes were made. 


\section{Keywords}

Subarachnoid hemorrhage, COVID-19, renin-angiotensin pathway, matrix metalloproteinase 9, outcomes

\section{Introduction}

In late 2019, coronavirus disease 2019 (COVID-19) began to spread throughout Wuhan, China. The severity of the virus ranged from asymptomatic cases to very severe symptoms and even death. By March of 2020, COVID-19 had spread throughout the world leading to government-mandated lockdowns, and the World Health Organization (WHO) implementing various public health measures to mitigate the spread of the virus [1-3]. COVID-19 has been associated with systemic inflammation, thrombosis, and neurological symptoms likely due to a diminished alternative renin-angiotensin (RAS) pathway [4]. The role of microvascular dysfunction is also emerging and warrants further investigation. To date, there are no widely available, effective therapeutics for COVID-19 [5].

In this review, we explore how the COVID-19 virus and the intensive care unit (ICU) treatment of severe COVID can contribute to subarachnoid hemorrhage (SAH). SAH is a devastating condition with substantial morbidity and mortality. SAH leads to severe vasospasm, triggered cerebral ischemia, brain edema, and blood-brain barrier disruption. This can result in increased intracranial pressure, decreased cerebral perfusion pressure, and finally apoptotic neurodegeneration of the brain [6] (Figure 1).

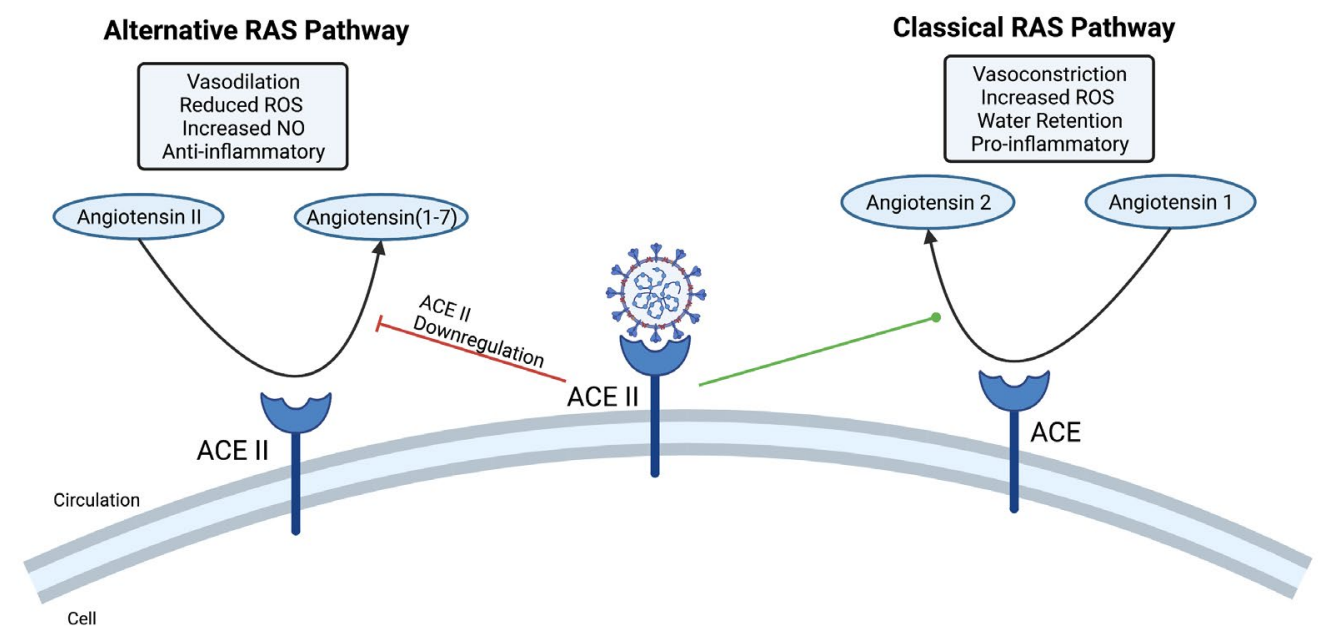

Figure 1. COVID-19 effect on the RAS pathway. The COVID-19 virus binds to the angiotensin-converting enzyme 2 (ACE2) receptor. This leads to a diminished alternative RAS pathway, which is known to have immunoregulatory effects including vasodilation, reduced reactive oxygen species (ROS), increased nitric oxide (NO) release, and anti-inflammatory effects. In turn, the classical RAS pathway dominates which leads to inflammation, vasoconstriction, increased ROS, and water retention. Created with BioRender.com

\section{SAH}

SAH is a severe medical emergency characterized by the presence of blood in the subarachnoid space, brain parenchyma, and occasionally ventricles [7-9]. Nontraumatic SAH is most often caused by a ruptured aneurysm, called an aneurysmal SAH (aSAH). This condition is associated with high rates of death due to initial blood loss, severe rise in intracranial pressure, the potential for aneurysmal rebleeding, and delayed cerebral ischemia $[6,8,10]$. In fact, up to $30 \%$ of patients suffering from aSAH develop delayed cerebral ischemia, which can lead to stroke or permanent brain damage [8]. Those most at risk for aSAH are women over 65 years, smokers, alcohol abusers, patients with hyperlipidemia, diabetics, and patients with heart disease. However, the leading cause of aSAH is hypertension [11, 12].

In patients who suffer from SAH, there is a drastic elevation in norepinephrine, pointing to an increase in sympathetic activity [13]. The hyperactivity typically stems from the medulla oblongata and the hypothalamus in response to increased intracranial pressure [12]. Heightened sympathetic tone contributes to elevations in blood pressure, cardiac dysfunction, neurogenic pulmonary edema, and the development of a systemic inflammatory response syndrome $[8,11,13]$. 


\section{COVID-19 predisposes patients to aneurysmal rupture}

Cerebral aneurysms are caused by a disruption of the normal laminar flow in cranial blood vessels [14]. As laminar blood flow turns turbulent, there is increased mechanical force on the blood vessel wall leading to endothelial cell stretching. This shift to turbulent flow can be caused by atherosclerotic plaques obstructing the blood flow, blood vessel stenosis, and hypertension [15].

Infection with COVID-19 has been shown to lead to hypertension and acute ischemic events [16, 17]. ACE2 is a receptor for the COVID-19 spike protein. When patients are infected with COVID-19, the virus binds to ACE2 leaving less ACE2 available to bind angiotensin (1-7) [4]. This ACE2/angiotensin (1-7) interaction is known as the alternative RAS pathway. This pathway has been shown to have anti-inflammatory effects and reduce sympathetic tone through the release of NO, vasodilation, diuresis, and reduced ROS $[4,18]$. Due to diminished alternative RAS activity, the ACE-angiotensin 2 pathway (classical RAS pathway) dominates. The classical RAS pathway leads to inflammation, vasoconstriction, water retention, and increased ROS. As a result, patients infected with COVID-19 are displaying diminished alternative RAS pathway and are at an increased risk for developing cerebral atherosclerotic plaques and blood vessel stenosis. This could cause turbulence in the cerebral blood vessels leading to the development of an aneurysm. Patients with occult aneurysms prior to COVID-19 infection are at an increased risk for aneurysmal rupture due to the hypertensive and ischemic effects of COVID-19.

Additionally, COVID-19 induced endothelial damage causes an increased expression of tissue factors leading to activation of the clotting cascade [19]. This phenomenon leads to elevated levels of D-dimer, fibrinogen degradation products, and bradykinin [20]. Clots that become lodged in the brain can lead to stroke; however, partial occlusion of a vessel can lead to turbulent flow and subsequent aneurysm or aneurysmal rupture.

The increased inflammation present in COVID-19 patients, from the mechanisms described above, can lead to increased permeability of the blood-brain barrier [21]. Breakdown of the blood-brain barrier can disrupt the matrix metalloproteinase-9 (MMP-9) [22]. Elevations in MMP-9 can lead to the dysregulated breakdown of arterial collagen. Thus, elevated MMP-9 and inflammatory cytokines in COVID-19 infection can lead to arterial instability and subsequent aSAH [23, 24].

\section{SAH and vasospasm}

Cranial vasospasm, or delayed narrowing of cerebral arteries, is a condition that appears in $70 \%$ of SAH patients 4-15 days after SAH [25-28]. This condition is severe and typically leads to death or permanent disability due to delayed cerebral ischemia and stroke. One possible explanation for post-SAH cerebral vasospasm is subarachnoid hemolysis leading to the accumulation of hemoglobin, oxyhemoglobin, methemoglobin, oxygen-free radicals, and inflammatory molecules [27]. Additionally, post-SAH neutrophil activation increases the levels of ROS in the brain leading to vasospasm [25]. aSAH patients with active COVID-19 infection and consequent vasoconstriction are at increased risk for vessel occlusion and vasospasm. Microvascular dysfunction may be a key contributor to this process as recently outlined by Kanat [2, 3].

\section{SAH complicated by ICU admission}

\section{COVID-19 ventilation requirements}

Increased ventilation requirements in severe COVID-19 patients present an increased risk for vasospasm [29]. Bassi et al. [30] demonstrated that mice under $50 \mathrm{~h}$ of mechanical ventilation displayed greater levels of hippocampal apoptosis and neuroinflammation when compared to the non-ventilated group. Additionally, the number of pro-inflammatory microglia cells and makers for astrocyte damage were higher in the mechanically ventilated group. Mechanical ventilation has also been associated with increases in pro-inflammatory cytokines such as tumor necrosis factor-alpha (TNF- $\alpha$ ), interleukin-6 (IL6), IL10, IL1 $\beta$ which can lead to inflammation in the brain [31]. This points to the idea that lung-protective mechanical 
ventilation in COVID-19 patients can lead to increased intracranial pressure and inflammation. These two observations increase the risk for patients to develop aneurysms and aSAH.

\section{Ventilator-associated pneumonia}

Patients who spend considerable time in the ICU from COVID-19 are susceptible to ventilator-associated pneumonia (VAP) [32]. VAP is characterized by the presence of multidrug-resistant, gram-negative bacteria and its prevalence has increased throughout the COVID-19 pandemic [33]. Patients recovering from SAH have been shown to have systemic immunosuppression [34]. As a result, VAP can lead to neuroinflammation and aneurysmal rebleeding in aSAH patients. This can greatly prolong the hospital stay.

\section{Decreased mobilization}

Early and frequent mobilization in patients recovering from aSAH has been shown to decrease the frequency and severity of vasospasm [35]. Patients with severe COVID-19 who are treated in the ICU over a prolonged period of time are often immobilized due to ICU-acquired weakness and muscle wasting [32, 36]. This immobilization and muscle weakness from COVID-19 ICU admission can add additional challenges for patients recovering from aSAH.

\section{Reversible cerebral vasoconstriction syndrome}

There has been a possible association between COVID-19 infection and reversible cerebral vasoconstriction syndrome (RCVS) [18, 37]. RCVS is characterized by alternating vasoconstriction and vasodilation. The rapid reperfusion in RCVS can lead to acute pressure on the cerebral vessel walls, leading to aneurysmal rupture and aSAH [18]. If patients are recovering from aSAH contract COVID-19, this RCVS phenomenon could severely hinder their recovery. Drastic changes in cranial arterial pressure can lead to aneurysm rebleeding and severe complications. In patients with suspected COVID-19 related RCVS, early treatment with anticoagulation therapy and nimodipine should be considered to avoid complications [37].

\section{Acute respiratory distress syndrome}

One of the most common pulmonary complications of aSAH is acute respiratory distress syndrome (ARDS). ARDS occurs in 11-50\% of aSAH patients and is associated with high morbidity and mortality [38]. ICU admitted COVID-19 patients are at risk for developing ARDS as a result of mechanical ventilation [39]. This mechanical ventilation-induced form of ARDS is termed ventilator-induced lung injury and is caused by uncontrolled pushing of air, increased tidal volume and driving pressure, and pulmonary asynchronies $[40,41]$. It is important to consider that aSAH patients undergoing ICU mechanical ventilation for COVID-19 management may be at increased risk for severe pulmonary distress.

\section{Vaccination against COVID-19 and SAH}

Vaccination against COVID-19 has become a critical initiative in controlling the COVID-19 pandemic. However, there have been some cases of patients suffering from vaccine-induced thrombotic thrombocytopenia (VITT) following vaccination with ChAdOx1 nCov-19 (AstraZeneca) or Ad26.COV2.S (Johnson\&Johnson) COVID-19 vaccines [42-45]. To date, this condition has not been described with the novel messenger RNA (mRNA) vaccines such as those from Moderna and Pfizer. VITT is described as concurrent thrombosis in the presence of thrombocytopenia. Interestingly, thrombotic events typically occur in the cerebral vessels and venous sinuses which can lead to hemorrhage.

Platelet factor 4 (PF4) is a positively charged chemokine that is released when platelets are activated [46]. In the well-described disease, heparin-induced thrombocytopenia (HIT), PF4 binds negatively charged heparin in the patients' serum [47]. This forms very large PF4-heparin complexes that have antigenic characteristics [46]. As a result, immunoglobulin G (IgG) autoantibodies against this complex can be formed which directly induces platelet activation and promotes crosslinking of platelet Fc $\gamma$ RIIA receptors [48]. The pathogenesis of VITT is very similar to HIT. 
Patients suffering from VITT have increased levels of anti-PF4 autoantibodies, similar to those of HIT. Likely, the negatively charged components of the vaccines such as the adenovirus glycoprotein, adjuvant components, and/or adenovirus DNA are able to bind PF4 similar to heparin [42, 49]. Autoantibodies against PF4 lead to thrombocytopenia and thrombosis [44]. These PF4-anionic complexes can also directly bind to endothelium causing the release of von Willebrand factor and increased expression of leukocyte adhesion molecules [46]. Thus, the spike protein interaction with the endothelium is not to blame for the rare adverse vaccination events.

\section{Conclusions}

The systemic effects of the COVID-19 virus may contribute to the development of cerebral aneurysms and subsequent aSAH. This is due to the inflammation, increased cytokines, vasoconstriction, ischemia, and blood hyper-viscosity caused by COVID-19. Some other viruses can cause similar findings, which will be a topic of further review. A key limitation for this current paper is that most studies to date are single case reports. This limits more extensive analysis and overall conclusions. As further retrospective data emerges from cohort studies, the role of a systematic review and meta-analysis is apparent. Further studies should be done to see if COVID-19 is a causative agent of SAH. Additionally, different treatment options for COVID-19 should be explored to reduce the systemic wide inflammation and ischemia. Possible treatments that can be explored are antiplatelet treatments, prophylactic heparin, Janus kinase (JAK) inhibitors, and Bruton's tyrosine kinase (BTK) inhibitors. These treatments could possibly reduce ischemic events and vasoconstriction; however, administration of blood thinners and antiplatelet regiments could also increase the risk of severe bleed if aneurysmal rupture occurs so should be administered cautiously.

\section{Abbreviations}

ACE2: angiotensin-converting enzyme 2

ARDS: acute respiratory distress syndrome

aSAH: aneurysmal subarachnoid hemorrhage

COVID-19: coronavirus disease 2019

HIT: heparin-induced thrombocytopenia

ICU: intensive care unit

IL6: interleukin-6

MMP-9: matrix metalloproteinase-9

NO: nitric oxide

PF4: platelet factor 4

RAS: renin-angiotensin

RCVS: reversible cerebral vasoconstriction syndrome

ROS: reactive oxygen species

SAH: subarachnoid hemorrhage

VAP: ventilator-associated pneumonia

VITT: vaccine-induced thrombotic thrombocytopenia

\section{Declarations}

\section{Author contributions}

BLW and EJP had equal contribution in design and writing. All authors contributed to manuscript revision, read and approved the submitted version. 


\section{Conflicts of interest}

The authors declare that they have no conflicts of interest.

\section{Ethical approval}

Not applicable.

\section{Consent to participate}

Not applicable.

\section{Consent to publication}

Not applicable.

\section{Availability of data and materials}

Not applicable.

\section{Funding}

Not applicable.

\section{Copyright}

(C) The Author(s) 2022.

\section{References}

1. Batcik OE, Kanat A, Cankay TU, Ozturk G, Kazancioglu L, Kazdal H, et al. COVID-19 infection produces subarachnoid hemorrhage; acting now to understand its cause: a short communication. Clin Neurol Neurosurg. 2021;202:106495.

2. Kanat A. Letter to the editor regarding "aneurysmal subarachnoid hemorrhage in COVID-19 patients: a case series”. World Neurosurg. 2021;154:199.

3. Kanat A. Letter to the editor regarding "subarachnoid hemorrhage and COVID-19: an analysis of 282,718 patients". World Neurosurg. 2021;155:200-1.

4. Chappell MC. Nonclassical renin-angiotensin system and renal function. Compr Physiol. 2012;2: 2733-52.

5. Gök G. COVID-19'da kardiyovasküler sistem tutulumunun epidemiyolojisi. In: Duman D, editor. COVID-19 ve kardiyovasküler sistem. 1. Baskı. Ankara: Türkiye Klinikleri; 2021. pp.1-3. Turkish.

6. Ozmen S, Altinkaynak K, Aydin MD, Ahiskalioglu A, Demirci T, Özlü C, et al. Toward understanding the causes of blood $\mathrm{pH}$ irregularities and the roles of newly described binuclear neurons of carotid bodies on blood $\mathrm{pH}$ regulation during subarachnoid hemorrhage: experimental study. Neuropathology. 2019;39:259-67.

7. Alotaibi AS, Mahroos RA, Al Yateem SS, Menezes RG. Central nervous system causes of sudden unexpected death: a comprehensive review. Cureus. 2022;14:e20944.

8. Macdonald RL. Delayed neurological deterioration after subarachnoid haemorrhage. Nat Rev Neurol. 2014;10:44-58.

9. Aydin MD, Kanat A, Yolas C, Soyalp C, Onen MR, Yilmaz I, et al. Spinal subarachnoid hemorrhage induced intractable miotic pupil. A reminder of ciliospinal sympathetic center ischemia based miosis: an experimental study. Turk Neurosurg. 2019;29:434-9.

10. Hutchinson PJ, Seeley HM, Kirkpatrick PJ. Factors implicated in deaths from subarachnoid haemorrhage: are they avoidable? Br J Neurosurg. 1998;12:37-40.

11. Li R, Lin F, Chen Y, Lu J, Han H, Yan D, et al. In-hospital complication-related risk factors for discharge and 90-day outcomes in patients with aneurysmal subarachnoid hemorrhage after surgical clipping and endovascular coiling: a propensity score-matched analysis. J Neurosurg. 2021;[Epub ahead of print]. 
12. Lozada-Martínez ID, Rodríguez-Gutiérrez MM, Ospina-Rios J, Ortega-Sierra MG, González-Herazo MA, Ortiz-Roncallo LM, et al. Neurogenic pulmonary edema in subarachnoid hemorrhage: relevant clinical concepts. Egypt J Neurosurg. 2021;36:27.

13. Naredi S, Lambert G, Edén E, Zäll S, Runnerstam M, Rydenhag B, et al. Increased sympathetic nervous activity in patients with nontraumatic subarachnoid hemorrhage. Stroke. 2000;31:901-6.

14. Tang H, Wang Q, Xu F, Zhang X, Zeng Z, Yan Y, et al. Underlying mechanism of hemodynamics and intracranial aneurysm. Chin Neurosurg J. 2021;7:44.

15. Saqr KM, Tupin S, Rashad S, Endo T, Niizuma K, Tominaga T, et al. Physiologic blood flow is turbulent. Sci Rep. 2020;10:15492.

16. Akpek M. Does COVID-19 cause hypertension? Angiology. 2021;[Epub ahead of print].

17. Alwahdy AS, Margaretha IY, Pramesti KS, Hamro N, Yuzella V, Nasution F, et al. Case series of intravenous thrombolysis for acute ischemic stroke in confirmed COVID-19 patients: single-centre experience. Egypt J Neurol Psychiatr Neurosurg. 2022;58:5.

18. Dakay K, Kaur G, Gulko E, Santarelli J, Bowers C, Mayer SA, et al. Reversible cerebral vasoconstriction syndrome and dissection in the setting of COVID-19 infection. J Stroke Cerebrovasc Dis. 2020;29:105011.

19. Cañas CA, Cañas F, Bautista-Vargas M, Bonilla-Abadía F. Role of tissue factor in the pathogenesis of COVID-19 and the possible ways to inhibit it. Clin Appl Thromb Hemost. 2021;27:10760296211003983.

20. Gando S, Wada T. Thromboplasminflammation in COVID-19 coagulopathy: three viewpoints for diagnostic and therapeutic strategies. Front Immunol. 2021;12:649122.

21. Cezar-Junior AB, Faquini IV, Silva JLJ, de Carvalho Junior EV, Lemos LEAS, Freire Filho JBM, et al. Subarachnoid hemorrhage and COVID-19: association or coincidence? Medicine (Baltimore). 2020;99:e23862.

22. Ursell MR, Marras CL, Farb R, Rowed DW, Black SE, Perry JR. Recurrent intracranial hemorrhage due to postpartum cerebral angiopathy: implications for management. Stroke. 1998;29:1995-8.

23. Poyiadji N, Shahin G, Noujaim D, Stone M, Patel S, Griffith B. COVID-19-associated acute hemorrhagic necrotizing encephalopathy: imaging features. Radiology. 2020;296:E119-20.

24. Yeo SJ, Kim SJ, Kim JH, Lee HJ, Kook YH. Influenza A virus infection modulates the expression of type IV collagenase in epithelial cells. Arch Virol. 1999;144:1361-70.

25. Dowlati E, Mualem W, Carpenter A, Chang JJ, Felbaum DR, Sur S, et al. Early fevers and elevated neutrophil-to-lymphocyte ratio are associated with repeat endovascular interventions for cerebral vasospasm in patients with aneurysmal subarachnoid hemorrhage. neurocrit care. 2021;[Epub ahead of print].

26. Barpujari A, Patel C, Zelmonovich R, Clark A, Patel D, Pierre K, et al. Pharmaceutical management for subarachnoid hemorrhage. Recent Trends Pharm Sci Res. 2021;3:16-30.

27. Ascanio LC, Gupta R, Tachie-Baffour Y, Chida K, Dmytriw AA, Enriquez-Marulanda A, et al. Effect of cerebrospinal fluid drainage on clinical outcomes following aneurysmal subarachnoid hemorrhage. J Clin Neurosci. 2022;97:1-6.

28. Wintermark M, Ko NU, Smith WS, Liu S, Higashida RT, Dillon WP. Vasospasm after subarachnoid hemorrhage: utility of perfusion CT and CT angiography on diagnosis and management. AJNR Am J Neuroradiol. 2006;27:26-34.

29. Gessler F, Mutlak H, Lamb S, Hartwich M, Adelmann M, Platz J, et al. The impact of tracheostomy timing on clinical outcome and adverse events in poor-grade subarachnoid hemorrhage. Crit Care Med. 2015;43:2429-38.

30. Bassi TG, Rohrs EC, Fernandez KC, Ornowska M, Nicholas M, Gani M, et al. Brain injury after $50 \mathrm{~h}$ of lung-protective mechanical ventilation in a preclinical model. Sci Rep. 2021;11:5105. 
31. Bilotta F, Giordano G, Sergi PG, Pugliese F. Harmful effects of mechanical ventilation on neurocognitive functions. Crit Care. 2019;23:273.

32. Maslove DM, Sibley S, Boyd JG, Goligher EC, Munshi L, Bogoch II, et al. Complications of critical COVID-19: diagnostic and therapeutic considerations for the mechanically ventilated patient. Chest. 2021; [Epub ahead of print].

33. Cusack R, Garduno A, Elkholy K, Martín-Loeches I. Novel investigational treatments for ventilatorassociated pneumonia and critically ill patients in the intensive care unit. Expert Opin Investig Drugs. 2022;31:173-92.

34. Coelembier C, Venet F, Demaret J, Viel S, Lehot JJ, Dailler F, et al. Impact of ventilator-associated pneumonia on cerebrospinal fluid inflammation during immunosuppression after subarachnoid hemorrhage: a pilot study. J Neurosurg Anesthesiol. 2022;34:e57-62.

35. Karic T, Røe C, Nordenmark TH, Becker F, Sorteberg W, Sorteberg A. Effect of early mobilization and rehabilitation on complications in aneurysmal subarachnoid hemorrhage. J Neurosurg. 2017;126:518-26.

36. Shah SO, Kraft J, Ankam N, Bu P, Stout K, Melnyk S, et al. Early ambulation in patients with external ventricular drains: results of a quality improvement project. J Intensive Care Med. 2018;33:370-4.

37. Scheer M, Harder A, Wagner S, Ibe R, Prell J, Scheller C, et al. Case report of a fulminant non-aneurysmal convexity subarachnoid hemorrhage after COVID-19. Interdiscip Neurosurg. 2022;27:101437.

38. Mazeraud A, Robba C, Rebora P, Iaquaniello C, Vargiolu A, Rass V, et al. Acute distress respiratory syndrome after subarachnoid hemorrhage: incidence and impact on the outcome in a large multicenter, retrospective cohort. Neurocrit Care. 2021;34:1000-8.

39. Moreno G, Carbonell R, Martin-Loeches I, Solé-Violán J, Correig I Fraga E, Gómez J, et al; COVID-19 SEMICYUC Working Group. Corticosteroid treatment and mortality in mechanically ventilated COVID-19-associated acute respiratory distress syndrome (ARDS) patients: a multicentre cohort study. Ann Intensive Care. 2021;11:159.

40. Wawrzeniak IC, Regina Rios Vieira S, Almeida Victorino J. Weaning from mechanical ventilation in ARDS: aspects to think about for better understanding, evaluation, and management. Biomed Res Int. 2018;2018:5423639.

41. AK AK, Anjum F. Ventilator-induced lung injury (VILI) [Updated 2021 Dec 15]. In: StatPearls. Treasure Island (FL): StatPearls Publishing; 2022.

42. Pavord S, Scully M, Hunt BJ, Lester W, Bagot C, Craven B, et al. Clinical features of vaccine-induced immune thrombocytopenia and thrombosis. N Engl J Med. 2021;385:1680-9.

43. Bérezné A, Bougon D, Blanc-Jouvan F, Gendron N, Janssen C, Muller M, et al. Deterioration of vaccine-induced immune thrombotic thrombocytopenia treated by heparin and platelet transfusion: insight from functional cytometry and serotonin release assay. Res Pract Thromb Haemost. 2021;5:e12572.

44. Cleaver J, Ibitoye R, Morrison H, Flood R, Crewdson K, Marsh A, et al. Endovascular treatment for vaccine-induced cerebral venous sinus thrombosis and thrombocytopenia following ChAdOx1 nCoV-19 vaccination: a report of three cases. J Neurointerv Surg. 2021;[Epub ahead of print].

45. Waraich A, Williams G. Haematuria, a widespread petechial rash, and headaches following the Oxford AstraZeneca ChAdOx1 nCoV-19 Vaccination. BMJ Case Rep. 2021;14:e245440.

46. Nevzorova TA, Mordakhanova ER, Daminova AG, Ponomareva AA, Andrianova IA, Le Minh G, et al. Platelet factor 4-containing immune complexes induce platelet activation followed by calpain-dependent platelet death. Cell Death Discov. 2019;5:106.

47. McGonagle D, De Marco G, Bridgewood C. Mechanisms of immunothrombosis in vaccine-induced thrombotic thrombocytopenia (VITT) compared to natural SARS-CoV-2 infection. J Autoimmun. 2021;121:102662. 
48. Goldman M, Hermans C. Thrombotic thrombocytopenia associated with COVID-19 infection or vaccination: possible paths to platelet factor 4 autoimmunity. PLoS Med. 2021;18:e1003648.

49. Pang $\mathrm{X}$, Liu H, He X, Ji T, Zhu Y, Cui Y. Potential anionic substances binding to platelet factor 4 in vaccine-induced thrombotic thrombocytopenia of ChAdOx1-S vaccine for SARS-CoV-2. Front Immunol. 2022;12:782335. 